\title{
BMJ Open Associations of primary care structures with polypharmacy and patient- reported indicators in patients with complex multimorbidity: a multicentre cross-sectional study in Japan
}

\author{
Takuya Aoki (D) , ${ }^{1,2}$ Yasuki Fujinuma, ${ }^{3}$ Masato Matsushima ${ }^{1}$
}

To cite: Aoki T, Fujinuma Y, Matsushima M. Associations of primary care structures with polypharmacy and patientreported indicators in patients with complex multimorbidity: a multicentre cross-sectional study in Japan. BMJ Open 2022;12:e054348. doi:10.1136/ bmjopen-2021-054348

- Prepublication history for this paper is available online. To view these files, please visit the journal online (http://dx.doi org/10.1136/bmjopen-2021054348).

Received 09 June 2021 Accepted 22 December 2021

\section{Check for updates}

\section{(C) Author(s) (or their} employer(s)) 2022. Re-use permitted under CC BY-NC. No commercial re-use. See rights and permissions. Published by BMJ.

${ }^{1}$ Division of Clinical Epidemiology, Research Center for Medical Sciences, The Jike University School of Medicine, Tokyo, Japan

${ }^{2}$ Section of Clinical

Epidemiology, Department of Community Medicine, Graduate School of Medicine, Kyoto University, Kyoto, Japan

${ }^{3}$ Centre for Family Medicine Development, Japanese Health and Welfare Co-operative Federation, Tokyo, Japan

Correspondence to Dr Takuya Aoki; taoki@jikei.ac.jp

\section{ABSTRACT}

Objectives Evidence supporting the effects of primary care structures on the quality of care for patients with complex multimorbidity, which is one of the most important challenges facing primary care, is scarce internationally. This study aimed to examine the associations of the types of primary care facilities with polypharmacy and patient-reported indicators in patients with complex multimorbidity, with a focus on differences between community clinics and hospitals.

Design Multicentre cross-sectional study.

Setting A total of 25 primary care facilities (19 community clinics and 6 small- and medium-sized hospitals).

Participants Adult outpatients with complex multimorbidity, which was defined as the co-occurrence of three or more chronic conditions affecting three or more different body systems within one person.

Primary outcome measure Polypharmacy, the PatientReported Experience Measure using the Japanese version of Primary Care Assessment Tool Short Form (JPCAT-SF) and the Patient-Reported Outcome Measure using selfrated health status (SRH).

Results Data were analysed for 492 patients with complex multimorbidity. After adjustment for possible confounders and clustering within facilities, clinic-based primary care practices were significantly associated with a lower prevalence of polypharmacy, higher JPCAT-SF scores in coordination and community orientation, and a lower prevalence of poor or fair SRH compared with hospital-based primary care practices. In contrast, the JPCAT-SF score in first contact was significantly lower in clinic-based practices. The associations between the types of primary care facilities and JPCAT-SF scores in longitudinality and comprehensiveness were not statistically significant.

Conclusions Clinic-based primary care practices were associated with a lower prevalence of polypharmacy, better patient experience of coordination and community orientation, and better SRH in patients with complex multimorbidity compared with hospital-based primary care practices. In the primary care setting, small and tight teams may improve the quality of care for patients with complex multimorbidity.
Strengths and limitations of this study

- This is the first study to report the associations of the types of primary care facilities with polypharmacy and patient-reported indicators in patients with complex multimorbidity.

- The study setting included different levels of primary care facilities that were widely distributed throughout Japan.

- Self-reported data on chronic conditions may have introduced misclassification bias and selection bias.

- The cross-sectional nature of the study precluded any causal inference from being made.

\section{INTRODUCTION}

Delivering care for complex problems such as multimorbidity is a core component of expert generalist practice. ${ }^{1}$ Multimorbidity is usually defined as the presence of two or more chronic conditions in an individual; however, the definition will identify large numbers of patients, many of whom will not have particularly complex needs. ${ }^{2}$ Therefore, 'complex' multimorbidity defined as three or more chronic conditions affecting three or more different body systems is suggested to better identify patients needing complex interventions than multimorbidity. ${ }^{34}$ Multimorbidity, especially 'complex multimorbidity', is one of the most important challenges facing primary care.

The quality of primary care is influenced by its structure, which is the organisational resource associated with the provision of care. Not only are primary care services provided exclusively by community clinics in some countries (eg, the UK), but hospitals may also have primary care functions, as is the case in the USA and Japan. Previous studies have reported the differences in the clinical and patient-reported indicators among types 
of primary care facilities in non-selective primary care patients. ${ }^{5-10}$ For example, some of these studies indicated that hospital-based primary care practices were associated with more low-value care and poorer performance of preventive care than community-based primary care practices. ${ }^{79}$ In addition, our previous study in primary care showed that patients who visited hospitals had higher first contact scores and lower community orientation scores compared with patients who visited clinics. ${ }^{10}$

Although the Japanese healthcare system does not necessarily distinguish between primary and secondary care and there is no gate-keeper system, primary care services are generally provided in both community clinics and outpatient departments of small-sized and medium-sized hospitals with less than 200 beds that are predominantly privately owned and managed. ${ }^{9} 11$ Japanese community clinics are generally run by a small team consisting of one full-time physician and a small number of nurses and medical assistants. On the other hand, primary care departments of small-sized and medium-sized hospitals are run by a large team consisting of more physicians, nurses, medical assistants and other healthcare professionals than clinics. ${ }^{10}$ Patients can visit any of these facilities without restricted access and additional out-of-pocket costs. ${ }^{10}$ In Japan, primary care in both practices has been typically delivered by primary care physicians trained in an internal medicine-based residency programme. The Japan Primary Care Association (JPCA), which was established with the merger of three academic societies in primary care, has certified primary care specialists since 2010. ${ }^{12}$ The Japanese Medical Specialty Board has started the new certification programme in $2018 .{ }^{13}$

In such a situation of primary care, clarifying what kind of care is provided in clinics and hospitals for patients with complex multimorbidity will provide guidelines for the direction of primary care provision in developed countries where the population is ageing. A previous study suggested that polypharmacy and patient-reported indicators, including the Patient-Reported Experience Measure (PREM) and Patient-Reported Outcome Measure (PROM), are core outcomes for multimorbidity research. ${ }^{14}{ }^{15}$ Therefore, in this study, we examined the associations of the types of primary care facilities with polypharmacy and patient-reported indicators in patients with complex multimorbidity, with a focus on differences between community clinics and hospitals.

\section{METHODS}

\section{Design, setting, and participants}

The data used in this study were collected from the primary care organisations reciprocal evaluation survey study (PROGRESS) 2018, which was conducted in primary care facilities nationwide. ${ }^{10}$ PROGRESS was a survey to collect data on clinical processes, patientreported indicators, healthcare utilisation, health conditions and sociodemographic characteristics among adult outpatients in primary care facilities to which a physician member of the JPCA belongs. A total of 25 facilities, consisting of 19 community clinics and 6 small-sized and medium-sized hospitals distributed in both urban and rural areas (Kanto, Chubu, Kinki and Kyushu areas), voluntarily participated in the study. The participating facilities included seven facilities from three networks of medical institutions. A self-administered questionnaire was distributed to all outpatients aged $\geq 20$ years who visited a primary care department in one of the participating facilities within a week of the survey period. We excluded patients who were seen for the first time at the participating facilities because it is difficult for them to assess their primary care experience. In addition, patients with severe mental disorders, such as advanced dementia, were also excluded.

Among adult outpatients who responded to the PROGRESS 2018, eligible participants in this study were patients with complex multimorbidity for whom the participating facility served as their usual source of care (USC). Complex multimorbidity was defined as the co-occurrence of three or more chronic conditions affecting three or more different body systems within one person. ${ }^{3}$ We collected data on the occurrence of 22 common chronic conditions using a structured questionnaire. Response options included hypertension, diabetes, dyslipidaemia, stroke, cardiac diseases, chronic respiratory diseases, digestive diseases, hepatobiliary and pancreatic diseases, kidney diseases, urological diseases, arthritis, rheumatism, lumbar diseases, osteoporosis, dementia, neurological diseases, mental disorders, endocrine diseases, malignancy, skin diseases, eye diseases and ear diseases. All chronic conditions were classified into the International Classification of Disease (ICD)-10 chapters to group chronic conditions by body system. $^{16}$

To identify an individual's USC in this study, three questions and an algorithm were used in the Primary Care Assessment Tool ${ }^{1718}$ : (1) is there a doctor that you usually go if you are sick or need advice about your health?; (2) is there a doctor that knows you best as a person? and (3) is there a doctor that is most responsible for your healthcare? A patient was considered to have a USC if he or she answered positively to any one of the three questions.

\section{Measures}

Polypharmacy

In this study, polypharmacy was defined as the concurrent use of $\geq 5$ prescription or over-the-counter (OTC) medications, a level which is the most commonly used definition for polypharmacy. ${ }^{19} 20$ The number of medications was assessed using a structured questionnaire. Patients were asked to provide a count of the medications that were chronically prescribed to them by both their USC and other sources of care, along with the number of OTC medications they used on a daily basis. Externally applied medications were excluded from the assessment. 
Adult outpatients visiting the participating facilities during the survey period $(\mathrm{N}=2,111)$

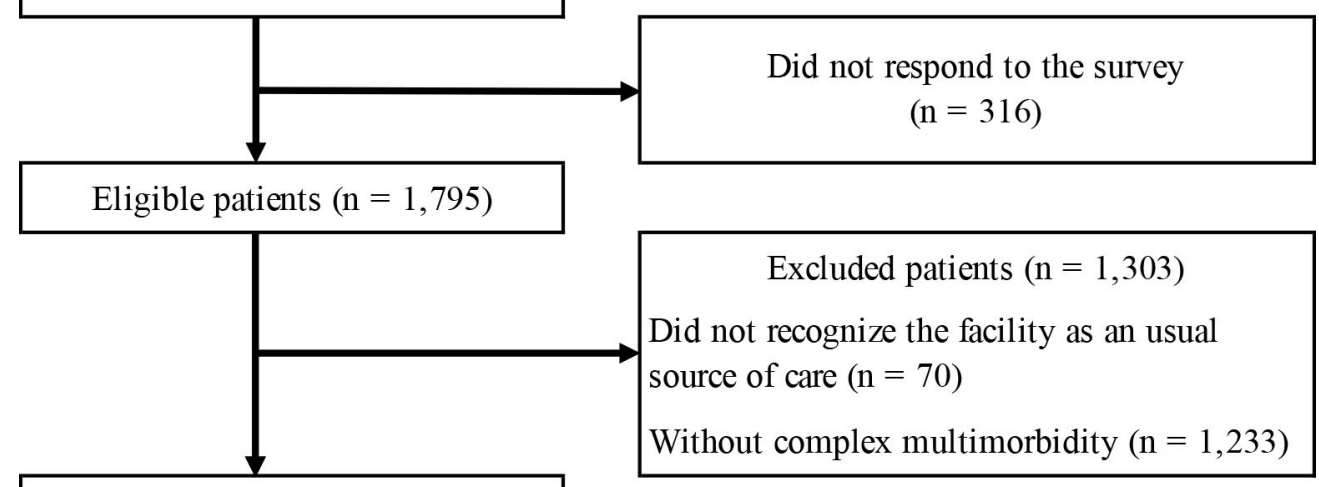

Patients in analyses $(n=492)$

Figure 1 Participant flow chart.

\section{Japanese version of Primary Care Assessment Tool}

We assessed PREM in primary care using the Japanese version of Primary Care Assessment Tool Short Form (JPCAT-SF). ${ }^{21}$ The JPCAT-SF is a 13-item tool comprising six domains representing five primary care attributes, including first contact, longitudinality, coordination, comprehensiveness and community orientation. The first contact domain reflects accessibility including outof-hours care. This tool consists of fewer items than the original Primary Care Assessment Tool, ${ }^{17}$ which was developed by the Johns Hopkins Primary Care Policy Center for better usability. A previous study showed that the JPCAT-SF has good reliability and validity. ${ }^{21}$ The scoring system of JPCAT-SF is structured as follows: each response on a 5 -point Likert scale ( 1 =strongly disagree, $2=$ somewhat disagree, $3=$ notsure, $4=$ somewhat agree and $5=$ strongly agree) is converted to an item score between 0 and 4 . The calculated means of item scores in the same domain are multiplied by 25 to yield domain scores ranging from 0 to 100 points, with higher scores indicating better performance. In the coordination domain, asking about the experiences of referral to a specialist, if respondents answered that they had never seen a specialist, 50 points (the middle number of the possible scores) were given.

\section{Self-rated health status}

In this study, PROM was assessed using self-rated health status (SRH). SRH is a common measure of overall health status and has been collected for international comparisons using general populations. ${ }^{14} \mathrm{SRH}$ has been reported to be associated with various health outcomes such as mortality, recovery after illness and health service utilisation. ${ }^{22}$ In this study, SRH was determined from the question 'In general, would you say your health is' with the response items (excellent, very good, good, fair, poor). We created a dichotomous variable for SRH (0 if excellent, very good, or good; 1 if fair or poor) ${ }^{23}$

\section{Statistical analysis}

Descriptive statistics were obtained for the patients' characteristics and the frequencies of chronic conditions by the types of primary care facilities. To examine the associations of primary care facility types with polypharmacy and poor or fair SRH, multivariable analyses were performed using a generalised linear mixed model with a logit link function. To confirm the robustness of the study findings, sensitivity analyses using a Poisson mixed effects model were conducted to examine the associations of primary care facility types with the number of total medications, prescription medications and OTC medications. In addition, we used a linear mixed effects model to examine the associations between primary care facility types and the JPCAT-SF scores. The random intercept models included a random effect for facilities and the following possible confounding variables as fixed effects: age, sex, years of education, annual household income, number of chronic conditions, eye and adnexa, digestive, and respiratory diseases, hospitalisation in the past 6 months and municipality population size where the participating facility was located. All possible confounding variables except for municipality population size were evaluated as categorical variables using a structured questionnaire. In this study, the municipality population size was categorised into two groups: small municipalities with $<50000$ people and large municipalities with $\geq 50000$ people. These categories were used because a population of 50000 was required for city designation, in accordance with Japan's Local Autonomy Law. For each analysis, we used a two-sided significance level of $\mathrm{p}=0.05$. Missing data on independent and dependent variables were handled by applying multiple imputation with 20 imputations using fully conditional specification. Statistical analyses were conducted using $\mathrm{R}$ V.3.6.3 (R Foundation for Statistical Computing, Vienna, Austria; www.R-project.org) and lme4 and mice packages. 
Table 1 Characteristics of patients with complex multimorbidity by types of primary care facilities

\begin{tabular}{|c|c|c|c|}
\hline \multirow[b]{2}{*}{ Characteristic } & \multirow[b]{2}{*}{ Total $(\mathrm{N}=492)$} & \multicolumn{2}{|c|}{ Types of primary care facilities } \\
\hline & & Clinic $(n=312)$ & Hospital $(n=180)$ \\
\hline \multicolumn{4}{|l|}{ Gender, n (\%) } \\
\hline Male & $220(44.7)$ & $152(48.7)$ & $68(37.8)$ \\
\hline Female & $258(52.4)$ & $152(48.7)$ & $106(58.9)$ \\
\hline Data missing & $14(2.8)$ & $8(2.6)$ & $6(3.3)$ \\
\hline \multicolumn{4}{|l|}{ Age (year), $\mathrm{n}(\%)$} \\
\hline $20-29$ & $2(0.4)$ & $1(0.3)$ & $1(0.6)$ \\
\hline 30-39 & $5(1.0)$ & $4(1.3)$ & $1(0.5)$ \\
\hline $40-49$ & $8(1.6)$ & $6(1.9)$ & $2(1.1)$ \\
\hline $50-59$ & $36(7.3)$ & $24(7.7)$ & $12(6.7)$ \\
\hline $60-69$ & $122(24.8)$ & $82(26.3)$ & $40(22.2)$ \\
\hline $70-79$ & $208(42.3)$ & $140(44.9)$ & $68(37.8)$ \\
\hline 80 or more & $107(21.7)$ & $54(17.3)$ & $53(29.4)$ \\
\hline Data missing & $4(0.8)$ & $1(0.3)$ & $3(1.7)$ \\
\hline \multicolumn{4}{|l|}{ Education, n (\%) } \\
\hline Less than high school & 114 (23.2) & $73(23.4)$ & $41(22.8)$ \\
\hline High school & $205(41.7)$ & $130(41.7)$ & $75(41.7)$ \\
\hline Junior college & $74(15.0)$ & $47(15.1)$ & $27(15.0)$ \\
\hline More than or equal to college & $88(17.9)$ & $56(17.9)$ & $32(17.8)$ \\
\hline Data missing & $11(2.2)$ & $6(1.9)$ & $5(2.8)$ \\
\hline \multicolumn{4}{|l|}{ Annual household income (million JPY), n (\%) } \\
\hline$<3.00$ (=US\$27 000) & $255(51.8)$ & $153(49.0)$ & $102(56.7)$ \\
\hline $3.00-4.99$ & $131(26.6)$ & $93(29.8)$ & $38(21.1)$ \\
\hline $5.00-6.99$ & $49(10.0)$ & $33(10.6)$ & $16(8.9)$ \\
\hline $7.00-9.99$ & $16(3.3)$ & $12(3.8)$ & $4(2.2)$ \\
\hline$\geq 10.00$ & $11(2.2)$ & $7(2.2)$ & $4(2.2)$ \\
\hline Data missing & $30(6.1)$ & $14(4.5)$ & $16(8.9)$ \\
\hline \multicolumn{4}{|l|}{ Hospitalisation in past 6 months, $n(\%)$} \\
\hline Yes & $75(15.2)$ & 37 (11.9) & $38(21.1)$ \\
\hline No & $412(83.7)$ & $272(87.2)$ & $140(77.8)$ \\
\hline Data missing & $5(1.0)$ & $3(1.0)$ & $2(1.1)$ \\
\hline \multicolumn{4}{|l|}{ Experience of visiting specialist, $\mathrm{n}(\%)$} \\
\hline Yes & $358(72.8)$ & $228(73.1)$ & $130(72.2)$ \\
\hline No & $94(19.1)$ & $61(19.6)$ & $33(18.3)$ \\
\hline Data missing & $40(8.1)$ & $23(7.4)$ & $17(9.4)$ \\
\hline Number of chronic conditions, median (IQR) & $3.0(3.0-4.0)$ & $3.0(3.0-4.0)$ & $3.0(3.0-4.0)$ \\
\hline \multicolumn{4}{|l|}{ Municipality population size, $\mathrm{n}(\%)$} \\
\hline$\geq 50000$ & $465(94.5)$ & $294(94.2)$ & $171(95.0)$ \\
\hline$<50000$ & $27(5.5)$ & $18(5.8)$ & $9(5.0)$ \\
\hline Number of regular medications, median (IQR) & $5.0(3.0-7.0)$ & $4.0(3.0-6.0)$ & $6.0(3.0-8.0)$ \\
\hline \multicolumn{4}{|l|}{ JPCAT-SF, mean (SD) } \\
\hline First contact & $53.5(27.4)$ & $47.2(27.6)$ & $64.2(23.6)$ \\
\hline Longitudinality & $75.8(19.4)$ & $76.4(18.2)$ & $74.7(21.4)$ \\
\hline Coordination & $67.4(28.5)$ & $69.7(27.9)$ & $63.2(29.2)$ \\
\hline Comprehensiveness (services available) & $62.0(26.1)$ & $62.2(25.4)$ & $61.6(27.4)$ \\
\hline
\end{tabular}


Table 1 Continued

\begin{tabular}{|c|c|c|c|}
\hline \multirow[b]{2}{*}{ Characteristic } & \multirow[b]{2}{*}{ Total $(\mathrm{N}=492)$} & \multicolumn{2}{|c|}{ Types of primary care facilities } \\
\hline & & Clinic (n=312) & Hospital $(n=180)$ \\
\hline Comprehensiveness (services provided) & $36.5(31.5)$ & $39.0(30.3)$ & $31.7(33.4)$ \\
\hline \multicolumn{4}{|l|}{ Self-rated health status, $\mathrm{n}(\%)$} \\
\hline Excellent & $5(1.0)$ & $3(1.0)$ & $2(1.1)$ \\
\hline Good & $248(50.4)$ & 167 (53.5) & $81(45.0)$ \\
\hline Fair & $161(32.7)$ & $89(28.5)$ & $72(40.0)$ \\
\hline Poor & $18(3.7)$ & $7(2.2)$ & $11(6.1)$ \\
\hline Data missing & $5(1.0)$ & $4(1.3)$ & $1(0.6)$ \\
\hline
\end{tabular}

JPCAT-SF, Japanese version of Primary Care Assessment Tool Short Form.

Patient and public involvement

No patient involved.

\section{RESULTS}

\section{Patients' characteristics}

A total of 1795 individuals out of 2111 adult outpatients responded to the PROGRESS 2018 (response rate: $85.0 \%)$. Among 1725 patients for whom the participating facility served as their USC, we included 492 (28.5\%) patients (312 clinic patients and 180 hospital patients) with complex multimorbidity (figure 1).

Table 1 shows the characteristics of patients with complex multimorbidity by the types of primary care facilities. The median (IQR) of the number of chronic

Table 2 Frequencies of chronic conditions in ICD-10 chapters among patients with complex multimorbidity, $\mathrm{N}(\%)$

\begin{tabular}{lll}
\hline & \multicolumn{2}{l}{$\begin{array}{l}\text { Types of primary care } \\
\text { facilities }\end{array}$} \\
\cline { 2 - 3 } ICD-10 chapter & $\begin{array}{l}\text { Clinic } \\
\text { ( } \mathbf{n}=312)\end{array}$ & $\begin{array}{l}\text { Hospital } \\
\text { (n=180) }\end{array}$ \\
\hline Circulatory & $250(80.1)$ & $136(75.6)$ \\
\hline Endocrine, nutritional, and metabolic & $197(63.1)$ & $108(60.0)$ \\
\hline Musculoskeletal and connective & $160(51.3)$ & $95(52.8)$ \\
\hline Eye and adnexa & $120(38.5)$ & $82(45.6)$ \\
\hline Digestive & $110(35.3)$ & $82(45.6)$ \\
\hline Genitourinary & $91(29.2)$ & $47(26.1)$ \\
\hline Ear and mastoid process & $62(19.9)$ & $37(20.6)$ \\
\hline Respiratory & $54(17.3)$ & $38(21.1)$ \\
\hline Neoplasms & $36(11.5)$ & $18(10.0)$ \\
\hline Skin and subcutaneous tissue & $30(9.6)$ & $14(7.8)$ \\
\hline Mental, behavioural and & $28(9.0)$ & $23(12.8)$ \\
neurodevelopmental & $5(1.6)$ & $2(1.1)$ \\
\hline Nervous system & &
\end{tabular}

ICD, International Classification of Disease. conditions was 3.0 (3.0-4.0) in both clinic-based practices and hospital-based practices. The number of concurrent medications in hospital-based practices was higher than that in clinic-based practices. There was a trend suggesting that the patients whose USC was the clinics had higher coordination, comprehensiveness (services provided), community orientation and lower first contact score compared with the patients whose USC was the hospitals.

Table 2 shows the frequencies of chronic conditions in the ICD-10 chapters of the study participants. The frequency of eye and adnexa, digestive, and respiratory diseases tended to be higher in the hospital group.

\section{Facility types and polypharmacy}

Table 3 shows the results of analyses using the generalised linear mixed model, modelling the unadjusted and adjusted associations between the types of primary care facilities and polypharmacy. After adjustment for possible confounders and clustering within facilities, clinic-based practices were significantly associated with a lower prevalence of polypharmacy compared with hospital-based practices (adjusted odds ratio $(\mathrm{aOR})=0.53,95 \%$ CI 0.35 to 0.82 ). Additionally, clinic-based practices were also significantly associated with a lower number of total medications and prescription medications compared with hospital-based practices (adjusted risk ratio $(\mathrm{aRR})=0.87$, $95 \%$ CI 0.78 to 0.97 and aRR $=0.86,95 \%$ CI 0.77 to 0.97 , respectively). In contrast, the association between the types of primary care facilities and the number of OTC medications was not statistically significant.

\section{Facility types and patient-reported indicators}

Table 4 shows the unadjusted and adjusted associations between the types of primary care facilities and patientreported indicators. After adjustment for possible confounders and clustering within facilities, clinicbased practices were significantly associated with higher JPCAT-SF scores in coordination and community orientation compared with hospital-based practices (adjusted 
Table 3 Comparison of polypharmacy in clinic-based practices and hospital-based practices among patients with complex multimorbidity* $(\mathrm{N}=492)$

\begin{tabular}{|c|c|c|c|c|}
\hline \multirow[b]{2}{*}{ Outcome } & \multirow{2}{*}{$\begin{array}{l}\text { Unadjusted } \\
\text { Relative risk }(95 \% \mathrm{Cl})\end{array}$} & \multirow[b]{2}{*}{$P$ value } & \multirow{2}{*}{$\begin{array}{l}\text { Adjusted† } \\
\text { Relative risk }(95 \% \mathrm{Cl})\end{array}$} & \multirow[b]{2}{*}{$P$ value } \\
\hline & & & & \\
\hline Polypharmacy $\ddagger$ & 0.55 (0.36 to 0.83$)$ & 0.005 & 0.53 (0.35 to 0.82$)$ & 0.004 \\
\hline \multicolumn{5}{|l|}{ Number of regular medications } \\
\hline Total & 0.85 (0.74 to 0.97$)$ & 0.020 & 0.87 (0.78 to 0.97$)$ & 0.014 \\
\hline Prescription medications & 0.85 (0.73 to 0.98$)$ & 0.029 & $0.86(0.77$ to 0.97$)$ & 0.014 \\
\hline Over-the-counter medications & 0.87 (0.60 to 1.27$)$ & 0.475 & 0.90 (0.63 to 1.32$)$ & 0.608 \\
\hline
\end{tabular}

${ }^{*}$ Reference group: hospitals; generalised linear mixed model; random effect on facility.

†Adjusted for age, sex, years of education, annual household income, number of chronic conditions, eye and adnexa, digestive, and respiratory diseases, hospitalisation in past 6 months, and municipality population size.

łUse of $\geq 5$ concurrent medications.

mean difference $=7.00,95 \%$ CI 1.23 to 12.77 and adjusted mean difference $=4.60,95 \%$ CI 0.03 to 9.17 , respectively). In contrast, clinic-based practices were associated with lower JPCAT-SF scores in first contact (adjusted mean difference $=-14.93,95 \%$ CI -26.06 to -3.80 ). The associations between the types of primary care facilities and JPCAT-SF scores in longitudinality and comprehensiveness were not statistically significant. In addition, clinicbased practices were significantly associated with a lower prevalence of poor or fair SRH compared with hospitalbased practices $(\mathrm{aOR}=0.51,95 \% \mathrm{CI} 0.34$ to 0.77$)$.

\section{DISCUSSION}

This study revealed that clinic-based primary care practices were significantly associated with a lower prevalence of polypharmacy and better SRH in patients with complex multimorbidity compared with hospital-based primary care practices. Furthermore, clinic-based practices were also significantly associated with higher JPCAT-SF scores in coordination and community orientation. For reference, a 6-point increase in the JPCAT coordination score has been associated with a $20 \%$ increment in advance care planning discussions with primary care professionals. ${ }^{24}$ In contrast, the JPCAT-SF score in first contact evaluating out-of-hours care was lower in clinic-based practices and the differences in longitudinality and comprehensiveness were not statistically significant, as seen in the findings from our previous study on non-selective primary care patients. ${ }^{10}$ The reason for the results regarding first contact may be that majority of Japanese clinics are solo practices making it difficult to provide out-of-hours care. These findings suggest that primary care structures play

Table 4 Comparison of patient-reported indicators in clinic-based practices and hospital-based practices among patients with complex multimorbidity* $(\mathrm{N}=492)$

\begin{tabular}{|c|c|c|c|c|}
\hline \multirow[b]{2}{*}{ PREM } & \multicolumn{2}{|l|}{ Unadjusted } & \multirow{2}{*}{$\begin{array}{l}\text { Adjusted } \dagger \\
\text { Mean difference }(95 \% \mathrm{Cl})\end{array}$} & \multirow[b]{2}{*}{$P$ value } \\
\hline & Mean difference $(95 \% \mathrm{Cl})$ & $P$ value & & \\
\hline \multicolumn{5}{|l|}{ JPCAT-SF $\ddagger$} \\
\hline First contact & $-18.77(-32.47$ to -5.07$)$ & 0.007 & $-14.93(-26.06$ to -3.80$)$ & 0.009 \\
\hline Longitudinality & $1.77(-1.81$ to 5.34$)$ & 0.333 & $1.07(-2.60$ to 4.73$)$ & 0.568 \\
\hline Coordination & 7.01 (1.34 to 12.69$)$ & 0.016 & $7.00(1.23$ to 12.77$)$ & 0.018 \\
\hline Comprehensiveness (services available) & $0.12(-6.33$ to 6.56$)$ & 0.971 & 0.85 (-5.18 to 6.88$)$ & 0.782 \\
\hline Comprehensiveness (services provided) & $4.71(-2.17$ to 11.59$)$ & 0.181 & $2.77(-4.05$ to 9.59$)$ & 0.427 \\
\hline \multirow[t]{2}{*}{ Community orientation } & $3.94(-0.95$ to 8.83$)$ & 0.115 & 4.60 (0.03 to 9.17$)$ & 0.049 \\
\hline & Unadjusted & & Adjusted $\dagger$ & \\
\hline PROM & OR $(95 \% \mathrm{Cl})$ & $P$ value & OR $(95 \% \mathrm{Cl})$ & $P$ value \\
\hline Poor or fair self-rated health status & 0.53 (0.36 to 0.77$)$ & 0.001 & $0.51(0.34$ to 0.77$)$ & 0.001 \\
\hline
\end{tabular}

*Reference group: hospitals; mixed effects model; random effect on facility.

†Adjusted for age, sex, years of education, annual household income, number of chronic conditions, eye and adnexa, digestive, and respiratory diseases, hospitalisation in past 6 months, and municipality population size.

$\ddagger$ All scores range from 0 to 100 .

JPCAT-SF, Japanese version of Primary Care Assessment Tool Short Form; PREM, Patient-Reported Experience Measure; PROM, Patient-

Reported Outcome Measure. 
an important role in the quality of care for patients with complex multimorbidity.

Polypharmacy, which increases adverse drug reactions and treatment burden, is an important indicator of multimorbidity. In clinic-based practices, better coordination among healthcare professionals, including specialists, may have contributed to a lower prevalence of polypharmacy in patients who have complex healthcare needs. ${ }^{25} 26$ As a result, in clinic-based practices, well-coordinated care and reduced polypharmacy may have led to better SRH, as shown in the previous studies. ${ }^{27} 28$

The advantages of clinic-based practices in care coordination, community orientation, and medication management may be attributed to its team structure. According to our findings, there is a possibility that small and tight team structures such as a 'teamlet' are more effective in administering care to patients with complex multimorbidity than large teams. The teamlet model is a team structure in which a clinician works with the same medical assistant or other support staff trained as 'health coaches' on a consistent basis. ${ }^{29}$ In clinic-based primary care practices in Japan, nurses often play important roles, such as health coaches, in support of a physician at previsit, between-visit and postvisit levels and communitybased interprofessional collaboration with care workers and social workers. Even in hospital outpatient departments, organising multiple small teams consisting of one physician and two or more other healthcare professionals as health coaches might be effective in improving the quality of care for patients with complex multimorbidity. Although the effects of health coaching have begun to be investigated in patients with multimorbidity, the studies have shown inconsistent results. ${ }^{30-32}$ In the future, intervention studies that also consider team structure are required.

To the best of our knowledge, this study was the first study to report the associations of the types of primary care facilities with polypharmacy and patient-reported indicators in patients with complex multimorbidity. The study setting included different levels of primary care facilities that were widely distributed throughout Japan, covering both urban and rural areas. In addition, the recovery rate for the questionnaire administered in this study was high $(85.0 \%)$. We adjusted possible confounding factors and clustering within facilities by using a mixed-effects model and allowed appropriate patient-level analysis.

However, the present study had some potential limitations. First, we used a self-reported survey to collect the data on chronic conditions. This method of assessment may have introduced selection bias. Indeed, participants did not include patients with diseases, such as advanced dementia. Second, data on the types of medications taken were not collected; thus, we could not evaluate the appropriateness of the medications. However, polypharmacy is known as an important risk factor for potentially inappropriate medications. ${ }^{33}$ Third, although we adjusted for possible confounding variables, unmeasured patient characteristics might have influenced the results.
For example, we adjusted for hospitalisation in the past 6 months, which potentially reflects the severity of chronic conditions; however, confounding by the severity of individual chronic conditions was not fully accounted for in the analyses. This might have overestimated the associations of the types of primary care facilities with polypharmacy and SRH. Fourth, given that the data were cross-sectional, a causal relationship between the types of primary care facilities and the outcomes cannot be definitively established. Fifth, this study was limited by the fact that the participating facilities were recruited publicly; thus, there is a possibility of representing facilities that have higher interests in the quality of medical care. This point should be considered when interpreting the results of the present study.

\section{Conclusion}

Clinic-based primary care practices were associated with a lower prevalence of polypharmacy, better patient experience of coordination and community orientation, and better SRH in patients with complex multimorbidity compared with hospital-based primary care practices. In contrast, hospital-based practices were associated with comparatively better patient experience of first contact including out-of-hours care. In the primary care setting, small and tight teams may improve the quality of care for patients with complex multimorbidity. Further research, which controls unmeasured confounding factors, is needed to confirm our findings.

Acknowledgements The authors thank the participating facilities belonging to the Japan Primary Care Association.

Contributors All authors (TA, YF and MM) of the paper contributed the conception or design of the work. TA performed the statistical analyses. TA, YF and MM interpreted the analyses. TA drafted the manuscript. All authors reviewed and edited the manuscript, contributed to the discussion of the data and performed critical review of the manuscript. All authors gave the final approval of the manuscript before submission. TA is the guarantor of the work and accepts full responsibility for the presented content.

Funding This work was supported by Institute for Health Economics and Policy, Japan (grant number N/A).

Competing interests TA and MM received lecture fees and lecture travel fees from the Centre for Family Medicine Development of Japanese Health and Welfare Co-operative Federation. TA and MM are advisers of the Centre for Family Medicine Development practice-based research network. MM's son-in-law worked at IQVIA Services Japan K.K. which is a contract research organisation and a contract sales organisation. MM's son-in-law works at SYNEOS HEALTH CLINICAL K.K. which is a contract research organisation and a contract sales organisation.

Patient and public involvement Patients and/or the public were not involved in the design, or conduct, or reporting, or dissemination plans of this research.

Patient consent for publication Not applicable.

Ethics approval This study involves human participants and was approved by the ethical committee of the Kyoto University Graduate School of Medicine (approval number: R1342). Participants gave informed consent to participate in the study before taking part.

Provenance and peer review Not commissioned; externally peer reviewed.

Data availability statement No data are available. Due to the nature of this research, participants of this study did not agree for their data to be shared publicly, so supporting data is not available.

Open access This is an open access article distributed in accordance with the Creative Commons Attribution Non Commercial (CC BY-NC 4.0) license, which 
permits others to distribute, remix, adapt, build upon this work non-commercially, and license their derivative works on different terms, provided the original work is properly cited, appropriate credit is given, any changes made indicated, and the use is non-commercial. See: http://creativecommons.org/licenses/by-nc/4.0/.

\section{ORCID iD}

Takuya Aoki http://orcid.org/0000-0002-8232-2155

\section{REFERENCES}

1 Reeve J, Dowrick CF, Freeman GK, et al. Examining the practice of generalist expertise: a qualitative study identifying constraints and solutions. JRSM Short Rep 2013;4:204253331351015.

2 Wallace E, Salisbury C, Guthrie B, et al. Managing patients with multimorbidity in primary care. BMJ 2015;350:h176.

3 Harrison C, Britt $\mathrm{H}$, Miller $\mathrm{G}$, et al. Examining different measures of multimorbidity, using a large prospective cross-sectional study in Australian general practice. BMJ Open 2014;4:e004694.

4 Storeng SH, Vinjerui KH, Sund ER, et al. Associations between complex multimorbidity, activities of daily living and mortality among older Norwegians. A prospective cohort study: the HUNT study, Norway. BMC Geriatr 2020;20:21.

5 Starfield B, Powe NR, Weiner JR, et al. Costs vs quality in different types of primary care settings. JAMA 1994;272:1903-8.

6 Shi L, Starfield B, Xu J, et al. Primary care quality: community health center and health maintenance organization. South Med J 2003;96:787-95.

7 Mafi JN, Wee CC, Davis RB, et al. Association of primary care practice location and ownership with the provision of low-value care in the United States. JAMA Intern Med 2017;177:838-45.

8 Hoa NT, Tam NM, Derese A, et al. Patient experiences of primary care quality amongst different types of health care facilities in central Vietnam. BMC Health Serv Res 2019;19:275

9 Aoki T, Fukuhara S. Associations of types of primary care facilities with adult vaccination and cancer screening in Japan. Int J Qual Health Care 2020;32:373-8.

10 Aoki T, Yamamoto Y, Fukuhara S. Comparison of primary care experience in hospital-based practices and community-based office practices in Japan. Ann Fam Med 2020;18:24-9.

11 Sakamoto H, Rahman M, Nomura S. Japan health system review. World Health Organization. Regional Office for South-East Asia 2018.

12 Japan Primary Care Association. Japan primary care association about us: activities. Available: http://www.primary-care.or.jp/jpca eng/activities.html [Accessed 19 Feb 2021].

13 Japanese Medical Specialty Board. Sougoushinryou-senmoni. Available: https://jmsb.or.jp/sogo/ [Accessed 19 Feb 2021].

14 Organisation for Economic Co-operation and Development. Measuring what matters: the patient-reported indicator surveys, 2019. Available: http://www.oecd.org/health/health-systems/ Measuring-what-matters-the-Patient-Reported-Indicator-Surveys.pdf [Accessed 19 Feb 2021].

15 Smith SM, Wallace E, Salisbury C, et al. A core outcome set for multimorbidity research (COSmm). Ann Fam Med 2018;16:132-8.
16 World Health Organisation. International statistical classification of diseases and related health problems 10th revision, 2013. Available: http://apps.who.int/classifications/icd10/browse/2010/en [Accessed 19 Feb 2021]

17 Shi L, Starfield B, Xu J. Validating the adult primary care assessment tool. J Fam Pract 2001;50:161-75.

18 Aoki T, Inoue M, Nakayama T. Development and validation of the Japanese version of primary care assessment tool. Fam Pract 2016;33:112-7.

19 Gnjidic D, Hilmer SN, Blyth FM, et al. Polypharmacy cutoff and outcomes: five or more medicines were used to identify communitydwelling older men at risk of different adverse outcomes. J Clin Epidemiol 2012;65:989-95.

20 Masnoon N, Shakib S, Kalisch-Ellett L, et al. What is polypharmacy? A systematic review of definitions. BMC Geriatr 2017:17:230.

21 Aoki T, Fukuhara S, Yamamoto Y. Development and validation of a concise scale for assessing patient experience of primary care for adults in Japan. Fam Pract 2020;37:137-42.

22 DeSalvo KB, Bloser N, Reynolds K, et al. Mortality prediction with a single general self-rated health question. A meta-analysis. J Gen Intern Med 2006;21:267-75.

23 Shibuya K, Hashimoto H, Yano E. Individual income, income distribution, and self rated health in Japan: cross sectional analysis of nationally representative sample. BMJ 2002;324:16-19.

24 Aoki T, Miyashita J, Yamamoto Y, et al. Patient experience of primary care and advance care planning: a multicentre cross-sectional study in Japan. Fam Pract 2017;34:206-12.

25 Kallio S, Kumpusalo-Vauhkonen A, Järvensivu T, et al. Towards interprofessional networking in medication management of the aged: current challenges and potential solutions in Finland. Scand J Prim Health Care 2016;34:368-76.

26 Toivo T, Airaksinen M, Dimitrow M, et al. Enhanced coordination of care to reduce medication risks in older home care clients in primary care: a randomized controlled trial. BMC Geriatr 2019;19:332.

27 Machón M, Larrañaga I, Dorronsoro M, et al. Health-related quality of life and associated factors in functionally independent older people. BMC Geriatr 2017;17:19.

28 Montiel-Luque A, Núñez-Montenegro AJ, Martín-Aurioles E, et al. Medication-related factors associated with health-related quality of life in patients older than 65 years with polypharmacy. PLoS One 2017; 12:e0171320.

29 Bodenheimer T, Laing BY. The teamlet model of primary care. Ann Fam Med 2007;5:457-61.

30 Park $\mathrm{Y}-\mathrm{H}$, Chang $\mathrm{H}$. Effect of a health coaching self-management program for older adults with multimorbidity in nursing homes. Patient Prefer Adherence 2014;8:959-70.

31 Panagioti M, Reeves D, Meacock R, et al. Is telephone health coaching a useful population health strategy for supporting older people with multimorbidity? An evaluation of reach, effectiveness and cost-effectiveness using a "trial within a cohort.". BMC Med 2018;16:80.

32 Shah V, Stokes J, Sutton M. Effects of non-medical health coaching on multimorbid patients in primary care: a difference-in-differences analysis. BMC Health Serv Res 2019;19:593.

33 Davies LE, Spiers G, Kingston A, et al. Adverse outcomes of polypharmacy in older people: systematic review of reviews. J Am Med Dir Assoc 2020;21:181-7. 